\title{
Con Mis Hijos No Te Metas: un estudio de discurso y poder en un grupo de Facebook peruano opuesto a la «ideología de género»
}

\author{
Daniela Meneses \\ Independiente \\ danielamenesessala@gmail.com
}

\section{RESUMEN $^{1}$}

En 2016, surgió en el Perú una campaña nacional contra el nuevo Currículo Nacional de la Educación Básica del Ministerio de Educación. También se creó el grupo de Facebook «Con Mis Hijos No Te Metas PERÚ-Oficial», que comenzó a acumular miles de «likes» y se utilizó para compartir información sobre el currículo $y$ para coordinar actividades y protestas. En el contexto de esta campaña, realicé una netnografía y análisis del discurso sobre las publicaciones y comentarios aparecidos en el grupo de Facebook. Partiendo de las ideas de Foucault, sostengo que los individuos religiosos que se oponen al currículo y participan en la página están ejerciendo poder pastoral, al actuar como pastores a cargo de guiar a un rebaño de cuerpos-almas lejos de esta «ideología de género" y hacia la salvación. Analizo cómo estos pastores también ejercen el poder disciplinario para normalizar los cuerpos-almas heterosexuales y el biopoder para asegurar la reproducción de la raza humana. Muestro cómo estos dos últimos poderes se reconfiguran a través del poder pastoral y tienen como objetivo final la salvación. Exploro cómo Dios ejerce el poder soberano a través de los pastores y ordena la condena eterna de los LGBTQI* que no siguen su camino y que aceptan la «ideología de género» impuesta en las escuelas. Sostengo que el ejercicio de poder soberano también se legitima a través del poder pastoral. Finalmente, argumento

Este texto se basa en mi tesis para obtener el MSc en Políticas Públicas, por la University College London, bajo la asesoría de la doctora Cathy Elliot. 
que la configuración específica del poder soberano en el grupo de Facebook puede entenderse como una instancia de necropoder.

Palabras clave: sexualidad, género, neoconservadurismo religioso, necropoder, poder pastoral, necropolítica, netnografía, Con Mis Hijos No Te Metas, Facebook.

\section{Con Mis Hijos No Te Metas: a study of discourse and power in a Peruvian Facebook group opposing «gender ideology»}

In 2016, a national campaign against the Ministry of Education 's new National Curricula for Basic Education emerged in Peru. A Facebook group with the name "Con Mis Hijos No Te Metas PERÚ-Oficial» ("Don't Mess With My Children PERU-Oficial», in English) also appeared. It started receiving thousands of «likes» and was used to share information about the curricula and coordinate activities and protests. In the context of this campaign, I conducted a netnography of the Facebook group and analyzed the discourse that appears in the page. Using Foucault's ideas of power as a point of departure, I argue that religious individuals that oppose the curricula and participate in the page are exercising pastoral power, and acting like pastors in charge of guiding a flock of bodies-souls away from this "gender ideology" and to salvation. I explore how pastors also exercise disciplinary power (seeking to normalize heterosexual bodies-souls) and biopower (hoping to assure the reproduction of mankind by making people engage only in heterosexual sex). I show how both these powers are reconfigured through pastoral power and have salvation as its aim. I also explore how God exercises sovereign power through the pastors, condemning to Eternal Damnation the LGBTQI* individuals that don 't follow his path and that accept the "gender ideology" being imposed in schools. I argue that this exercise of sovereign power is legitimized through pastoral power. Finally, I maintain that the specific configuration of sovereign power in the Facebook group can be understood as an instance of necropower.

Keywords: gender ideology, Con Mis Hijos No Te Metas, education, gender, pastoral power, necropower, necropolitics, queer necropolitics, netnography, etnography 


\section{LIMA EMPAPELADA}

En diciembre de 2016, Lima se despertó con pancartas colocadas en una de las avenidas principales de la ciudad. Sobre un fondo rosado y azul se podía leer: «Con mis hijos no te metas». En las siguientes semanas, aparecieron letreros similares en todo el país. Un grupo de Facebook relacionado, denominado «Con Mis Hijos No Te Metas PERÚ-Oficial» (de ahora en adelante, CMHNTM PERÚ), comenzó a recibir miles de likes y se usó para compartir información sobre el nuevo Currículo Nacional de la Educación Básica del Ministerio de Educación y coordinar actividades y protestas. La intención detrás de la campaña era clara: hacer que el gobierno cambie el currículo.

\section{Figura 1}

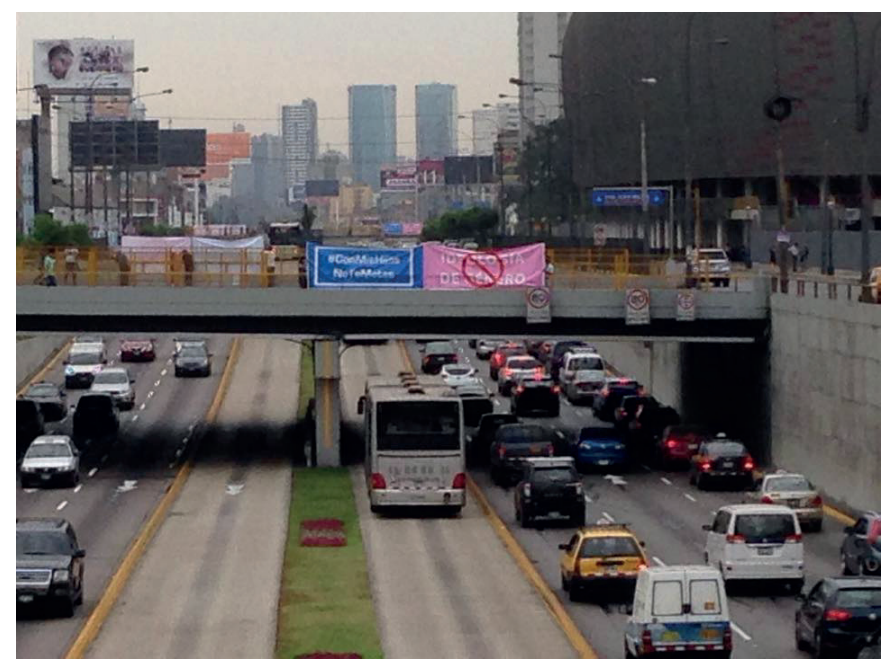

«\#ConMisHijosNoTeMetas /[NO A LA] IDEOLOGÍA DE GÉNERO» Foto: CMHNTM PERÚ. 09.01.17 
Según los organizadores de la campaña, el problema del plan de estudios es que introducía en las escuelas lo que ellos llaman «ideología de género». Con eso se refieren a la idea de que «no se nace únicamente varón o mujer, como la naturaleza ha establecido, sino que la identidad 'de género' se construye a partir de vivencias que uno tiene». Además de falsa, para ellos se trata de una creencia peligrosa, que hará que «con el paso de los años se induciría a que los niños digan 'me siento una niña' y las niñas digan 'yo creo que soy un niño'; y esto se tendría que ver como algo absolutamente normal» («Volante», s.d.).

Una revisión de la versión del currículo que ellos critican permite ver que no hay ninguna mención ni alusión al intento de cambiar las sexualidades de los niños. Sí hay una sección sobre género: sobre igualdad de género. Esa sección establece, por ejemplo, que debe haber una «igual valoración de los diferentes comportamientos, aspiraciones y necesidades de mujeres y varones», y que «si bien aquello que consideramos 'femenino' o 'masculino' se basa en una diferencia biológica-sexual, estas son nociones que vamos construyendo día a día, en nuestras interacciones» (Ministerio de Educación, 2016, p. 16). Debido a que los organizadores de la campaña creen que solo hay dos sexos y que ningún aspecto de la sexualidad se construye, denuncian estas afirmaciones como falsas. Leen cualquier mención a la palabra «género» en los planes de estudio como un signo del contrabando de «ideología de género $»^{2}$ del gobierno a las aulas, disfrazado de preocupación por la igualdad. Temen que, bajo este plan de estudios, se haga que los niños cuestionen sus «géneros naturales».

La campaña contra el currículo ha provocado un debate nacional sobre género y educación, y ha contado con el apoyo de poderosos políticos («Fujimorismo respaldó», 04.03.17). En respuesta a las inquietudes expresadas en este debate, en marzo de 2017 el gobierno hizo algunas modificaciones en el currículo, con la esperanza de que definiciones más detalladas de términos como género, identidad y educación sexual calmaran a las personas que se oponen a él («Currículo Escolar», 09.03.17). Sin embargo, no ha sido suficiente para el grupo, que inició acciones legales contra el documento,

Las protestas contra la «ideología de género» (tanto en la política educativa como en otras áreas) han tenido lugar en diversos países latinoamericanos, como Bolivia y Colombia (Moreno, 2016; Sánchez, 2016). Sin embargo, el tema sigue

Hablo de «ideología de género» entre comillas para enfatizar que no estoy de acuerdo con las ideas que implica: que los niños están en peligro, y que es perjudicial hablar del género como una construcción y categoría distinta del sexo. 
siendo altamente inexplorado en la academia. Dado que, en el caso peruano, los manifestantes se identifican como cristianos evangélicos y como católicos (Castro, 2017), y la religión parece ser el principal impulsor de la protesta, mi investigación se centrará en la oposición religiosa a los planes de estudio. Más que enfocarme en el discurso de los políticos y otras voces que suelen aparecer en los medios tradicionales, me concentraré en el discurso de los ciudadanos promedio: esas personas usualmente escondidas en el anonimato, que salen a protestar y que son la base de las movilizaciones.

Para lograr este objetivo, estudiaré los discursos que aparecen en la página de Facebook de CMHNTM PERÚ, una página que, en julio de 2017, cuando este trabajo comenzó a redactarse, tenía ya más de 150000 miembros. Utilizando la netnografía (la etnografía de la web), y el análisis del discurso, mostraré que los participantes religiosos de CMHNTM PERÚ están ejerciendo el poder pastoral con el objetivo de influir en otros y llevarlos a rechazar la «ideología de género». Actúan como pastores encargados de guiar al rebaño lejos de esta «ideología» y hacia la salvación. En mi análisis, mostraré que el poder pastoral reconfigura el ejercicio del poder disciplinario, del biopoder y del poder soberano en CMHNTM PERÚ. Además, el estudio del poder en CMHNTM PERÚ será enriquecido con la discusión de las ideas de Foucault sobre el racismo y el concepto de necropoder de Achille Mbembe.

\section{ALGUNAS CUESTIONES METODOLÓGICAS}

Robert Kozinets desarrolló por primera vez el término netnografía para referirse al estudio de una realidad existente en una sociedad en línea (Kozinets, 2015, pp. 54 y 79). La netnografía insta a los investigadores a sumergirse y estudiar espacios como las páginas de Facebook, los foros, las páginas de Twitter, Instagram, etc. Las netnografías comparten con las etnografías el hecho de que necesitan (i) que el investigador se sumerja «en una comunidad, una cohorte, una localidad o un clúster de sujetos relacionados», o (ii) que muestre un «enfoque que se preocupa [...] por recopilar los significados que las personas bajo estudio atribuyen a su realidad social y política» (Schatz, 2009, p. 5). En esta netnografía, me sumerjo en CMHNTM Perú, y trato de entender el significado que las personas religiosas atribuyen a su realidad. Realizar una netnografía me permite relacionarme con las opiniones de miles de personas que, antes de la existencia de las redes sociales, podrían no haber tenido una plataforma para sus voces. Este acceso es central para mi investigación, porque quiero estudiar cómo ejercitan el poder los ciudadanos «de a pie». 
Los datos recolectados en la netnografía fueron analizados a través del análisis del discurso. Siguiendo a Foucault, creo que los discursos no son «una mera intersección de cosas y palabras» o «grupos de signos», sino «prácticas que forman sistemáticamente los objetos de los que hablan» (Foucault, 2002, pp. 53-54). Aparecen en diferentes textos, imágenes y narrativas (Shepherd, 2006, p. 20), volviéndose «característicos de la manera de pensar o el estado del conocimiento en cualquier momento específico» (Hall, 2004, pp. 72-73). El discurso fija el significado solo para un contexto y momento en el tiempo particular (Shepherd, 2006, p. 20; Carabine, 2003, p. 268) y al hacerlo «transmite y produce poder» (Foucault, 1998 p. 101). Se trata de prácticas de poder (Shepherd, 2010, p. 145) que definen qué es la realidad, y que defienden su existencia continua (Shepherd, 2006, p. 20). Esta relación entre discurso y poder está en el centro de este trabajo, ya que me concentro en cómo y qué poder se ejercita y produce a través del discurso.

\section{Figura 2}

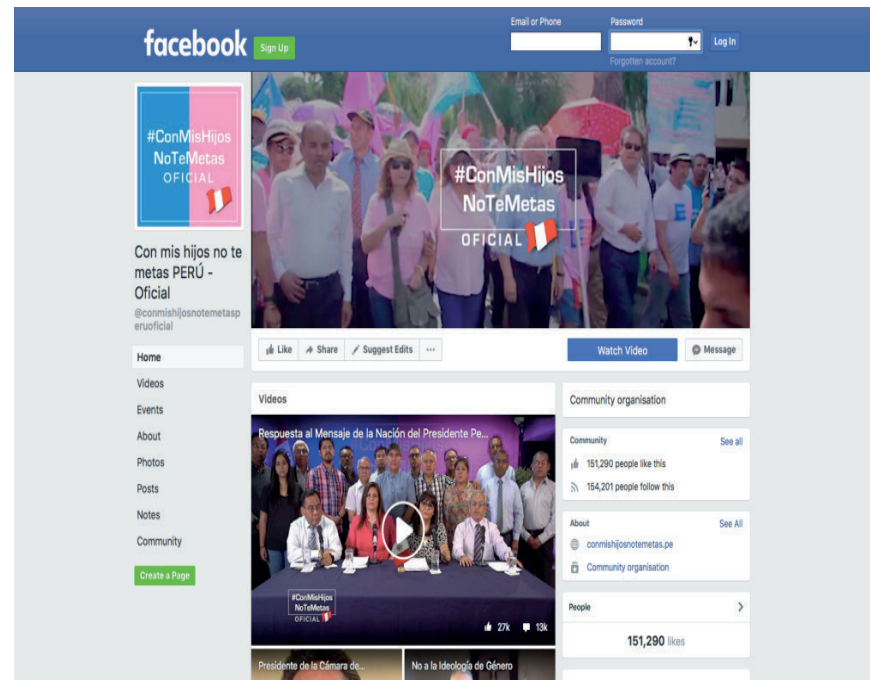

CMHNTM PERÚ. Captura de pantalla: 12.08.17

Para esta netnografía elegí el grupo de Facebook CMHNTM PERÚ porque, aunque hay otros grupos de Facebook peruanos que se refieren a la «ideología de género», esta es la página más popular que se centra en el problema del currículo educacional. Al momento de elaborar este trabajo, CMHNTM PERÚ tenía más de 150000 likes y estaba muy activo. 
La netnografía fue puramente observacional, pues busqué una inmersión que me permitiera estudiar las interacciones en su entorno natural, sin ser afectadas por mi presencia (Taylor, 2003, p. 27). Estudié los comentarios publicados en la página desde que se creó, en noviembre de 2016, hasta junio de $2017^{3}$. Luego de guardar todos las publicaciones y comentarios en archivos PDF, los importé a NVivo y los clasifiqué en diferentes nodos, que respondían a distintos subtópicos. Aunque leí todos los tipos de comentarios para tener una idea de los discursos que aparecen en la página, en los nodos solo incluí aquellos sobre los que había suficientes indicios para decir que habían sido escritos por personas religiosas (por ejemplo, cuando hacían referencia a Dios o a la Biblia). Esta decisión tiene el inconveniente de excluir aquellos comentarios de religiosos que no mencionaban elementos que los hicieran reconocibles como tales. También, que no había forma de diferenciar diferentes grados de acercamiento a la religión.

Los nodos más relevantes fueron los siguientes:

1. Castigo final: comentarios que aludían a la condena eterna.

2. Enfermedad: comentarios que identificaban a los individuos LGBTQI* como enfermos o con sida.

3. Convertir a LGBTQI*: comentarios que reflejan la idea de que la heterosexualidad es algo que se puede alcanzar.

4. Guía: comentarios que aluden a la guía de otros.

5. Gobierno: comentarios que mencionaban al gobierno o a autoridades.

6. Futuro niños: comentarios que se refieren a los niños como el futuro de la humanidad.

7. Defensa: comentarios sobre la idea de que la «ideología de género» es algo de lo que hay que defenderse.

8. Reproducción: comentarios que aluden a la reproducción de la raza humana.

9. Biblia: comentarios que se refieren a la Biblia o a la palabra de Dios.

10. Ciencia: comentarios que se refieren a la ciencia.

11. Diablo: comentarios que mencionan al diablo.

12.Derechos: comentarios sobre el derecho de los padres, de los niños o de las personas religiosas.

13.Dios: comentarios que mencionan a Dios o Jesús.

3 Las acciones legales en torno al currículo ocurrieron luego del período de estudio. 
14. El Niño: comentarios relacionados al Fenómeno del Niño o a los huaicos.

15.Familia: comentarios que se refieren a la familia.

En el proceso de clasificación de nodos, se hizo bastante evidente que sería imposible leer y trabajar con cada uno de los miles de comentarios religiosos. Así, opté por comenzar con las primeras fechas de cada mes. Cuando sentía que había alcanzado el «agotamiento» y tenía ya clasificados en nodos los aspectos más importantes, buscaba si en el mes había eventos nuevos o importantes que podrían haber afectado el discurso. Hecho esto, repetía el proceso con el mes siguiente.

Luego me concentré en analizar la información que tenía en los nodos, estableciendo cuál era el discurso principal. Más adelante presentaré algunos de los textos representativos que forman el discurso.

Hay tres advertencias necesarias antes de continuar. La primera es que únicamente me centré en los comentarios religiosos que se oponían al currículo. Aunque la mayoría de comentarios religiosos eran en ese sentido, también había creyentes a favor del currículo y que no creían en la «ideología de género». Así, cualquier mención a los participantes religiosos debe interpretarse como una referencia a los participantes religiosos que se oponen al currículo.

La segunda es que el que este sea un trabajo posestructuralista no significa que cualquier cosa vale. Siguiendo a Schwartz-Shea y Yanow, creo que la transparencia, la reflexividad, la sistematicidad y la confiabilidad deben guiar, y han guiado, mi investigación (Schwartz-Shea y Yanow, 2012, p. 100).

La tercera es que, siendo una mujer feminista y agnóstica, he procedido en esta investigación con el deseo de entender a los participantes de CMHNTM PERÚ. Esto ha sido retador, porque personalmente soy muy crítica a sus ideas, a su concepción de la homosexualidad y en general a su mensaje de fondo. Sin embargo, mi rol en este caso no ha sido juzgar, sino investigar el fenómeno. Por eso he buscado a lo largo de todo este trabajo estar consciente de mi posición (positionality) (Schwartz-Shea y Yanow 2012, p. 105). Así, espero que quede claro que cuando presento ideas como, por ejemplo, que la Biblia es una fuente de autoridad, o que hay un castigo eterno para quienes no cumplen con la palabra de Dios, me estoy refiriendo exclusivamente a las ideas de los participantes de CMHNTM PERÚ.

\section{LA ÉTICA DE INVESTIGAR EN FACEBOOK}

Facebook proporciona nuevos caminos emocionantes para los investigadores, pero también nuevos dilemas éticos. De acuerdo con las regulaciones de la uni- 
versidad para la que este artículo fue inicialmente trabajado (University College London), dado que en este caso utilicé únicamente datos que estaban compartidos en una página pública y que estaban disponibles sin iniciar sesión en Facebook, no requerí aprobación del Comité de Investigación de Ética interno.

A pesar de lo anterior, también consideré otros factores. Primero, pensé en el impacto que mi investigación podría tener en las personas en cuyas voces me enfocaría. Aquí, una primera idea es que los participantes de este grupo de Facebook no pueden tener una expectativa razonable de que sus ideas únicamente serían escuchadas por sus pares, pues este grupo es un lugar donde otras personas críticas al movimiento están continuamente comentando. Más que eso, para mí resulta claro que los participantes en CMHNTM PERÚ están tratando de hacer oír su voz. En este contexto, no podría estar más de acuerdo con Basset y O'Riordan:

Si un individuo o grupo ha optado por utilizar internet para publicar sus opiniones, entonces el investigador debe considerar su decisión en la misma medida que lo haría con una publicación similar en los medios impresos tradicionales. Una ética de investigación demasiado protectora corre el riesgo de disminuir el capital cultural de quienes producen a través de las tecnologías de internet y de contribuir inadvertidamente a continuar con su marginación (Basset y O'Riordan, 2002, citado por Kozinets, 2015, p. 136).

Otro aspecto a tomar en cuenta es que los comentarios no se referían ni constituían delito alguno ni proporcionaron información sensible sobre los participantes en la página. Además, no estoy compartiendo aquí los nombres de las personas que comentaron ni las fechas en las que lo hicieron, porque esto no es relevante para la investigación, y porque haría más fácil identificarlas, una identificación que no aporta nada a este trabajo (Halperin y Heath, 2012, p. 180; Pachirat, 2013, p. 84).

En aras de la transparencia, escribí al grupo de Facebook para informar a los administradores que estaba haciendo un trabajo de investigación en su sitio y ofrecer discutir los detalles de mi estudio. Quería entender cómo se sentían sobre la investigación y qué puntos potenciales podrían preocuparles. El mensaje fue leído, pero no obtuve respuesta.

\section{PODER PASTORAL: EL REBAÑO QUE NECESITA SALVACIÓN}

En mi trabajo de campo en CMHNTM PERÚ encontré que los participantes religiosos guían a otros, como si fueran su rebaño, a la salvación. A pesar de 
que no son representantes «oficiales» de una institución religiosa, actúan como mensajeros de Dios y se convierten ellos mismos en pastores.

Para Foucault, el poder no solo es represivo, sino también productivo (Foucault, 1991, pp. 60-61) y está en todas partes (Foucault, 1998, p. 93). El poder en la base de la sociedad no es una mera reproducción del poder producido por los estratos superiores (Hall, 2004, p. 77); Foucault nos insta a prestar atención a la «microfísica del poder»: «los muchos circuitos, tácticas, mecanismos y efectos a través de los cuales circula el poder» (Hall, 2004, p. 77). Con poder pastoral, Foucault se refiere al poder ejercido por un pastor que guía a cada miembro individual de su rebaño a la salvación (Foucault, 2007, pp. 126, 129). Tradicionalmente, la Iglesia cristiana gobernó la vida terrestre del rebaño (Foucault, 2007, p. 165) y estableció méritos y faltas por las acciones de los individuos. Al final, Dios los sopesaría y determinaría quién obtuvo la salvación (Foucault, 2007, p. 173). Después de los desarrollos científicos, como la física de Galileo, el cristianismo comenzó a entender a Dios más como una fuente de leyes generales que ya no interviene directamente en los asuntos terrestres (Foucault, 2007, pp. 234-235). El gobierno moderno también ejerció el poder pastoral, al entender que debía cuidar a toda la rebaño-población y a cada oveja-individuo (Simons, 2013, p. 312).

Foucault consideraba su trabajo sobre el poder pastoral aún como un bosquejo (Foucault, 2007, p. 135) y admitió que podría haberse equivocado al afirmar que el siglo XVIII vio el fin del poder pastoral, porque este persistió como una «organización y modo de funcionamiento» (Foucault, 2007, p. 148). Trabajos recientes han usado este concepto para entender los fenómenos contemporáneos que no necesariamente se refieren a autoridades religiosas institucionales [por ejemplo, el poder ejercido por asesores genéticos (Rose, 2007), trabajadores médicos en prisiones (Federman y Holmes, 2005), o profesores (McCuaig, 2012)].

Durante mi trabajo de campo, encontré que los comentaristas-pastores buscan constantemente guiar a otros hacia el camino correcto. Parecen muy conscientes de su tarea, y hablan repetidamente sobre «guiar» a los demás hacia la verdad de Dios y de Jesús, mientras «denuncian» lo que está mal con los nuevos planes de estudio. Aquí hay dos ejemplos del tipo de comentarios que aparecen constantemente en la página: «[...] sabemos el camino que llevan apartado del Señor, y queremos que cambien! [...]»; «[...]debemos decir al que no conoce esta palabra q Cristo lo ama y que quiere salvar su alma y q deje toda práctica pecaminosa y así alcance la salvacion [...]». «LO QUE ESTAMOS LLAMADOS... NOSOTROS ES A PREDICAR SU PALABRA [de Dios...]». 
La «palabra» que los participantes religiosos comparten es la verdad sexual. El rebaño debe darse cuenta de que Dios creó al hombre y la mujer, y nada «en el medio» (una expresión que se usa constantemente para referirse a los individuos LGBTQI*). Desde su punto de vista, los homosexuales existen, pero son una «abominación», un producto del poder del diablo: «Entiendan que la homoxualidad es un espiritu diabólico Que se le mete a la persona». Al decir también que los homosexuales no pertenecen al «Reino de Dios», los pastores están construyendo la homosexualidad y la religión como mutuamente excluyentes.

Los pastores en la página no diferencian las múltiples manifestaciones de las no heterosexualidades. La palabra «homosexual» se usa frecuentemente para referirse a todas las personas LGBTQI*. En las imágenes que los participantes comparten, los no heterosexuales a menudo se representan como hombres trans. De hecho, algunos pastores utilizan imágenes, fácilmente compartibles, para ridiculizar las identidades trans. El mensaje en estas imágenes resuena con el temor que tienen de que «los niños digan 'me siento una niña'» («Volante», s.d.).

Figura 3

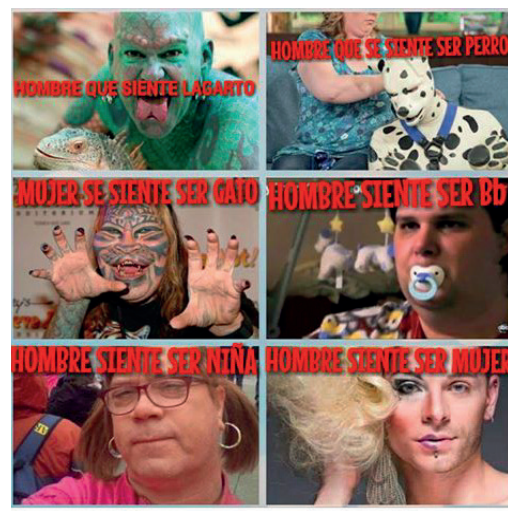

CMHNTM PERÚ.
Figura 4

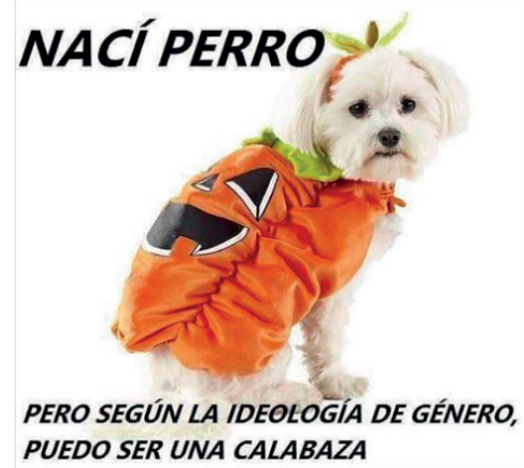

CMHNTM PERÚ.

La Biblia y la palabra de Cristo son la fuente que da autoridad al conocimiento compartido por los pastores, y es lo que en este contexto hace que su discurso sea verdadero (Hall, 2003, pp. 73-74). Es ese libro sagrado lo que les permite ser salvados y transmitir no solo el camino de la salvación, sino también las consecuencias para aquellos que no lo sigan. En este respecto, las imágenes también se convierten en un vehículo para compartir la palabra de Dios, uno mucho menos intimidante que un libro largo y antiguo. 
Figura 5

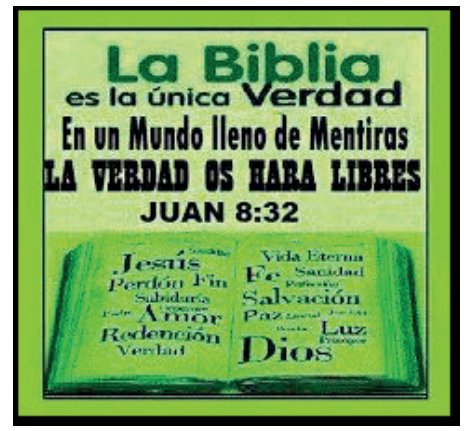

CMHNTM PERÚ.
Figura 6

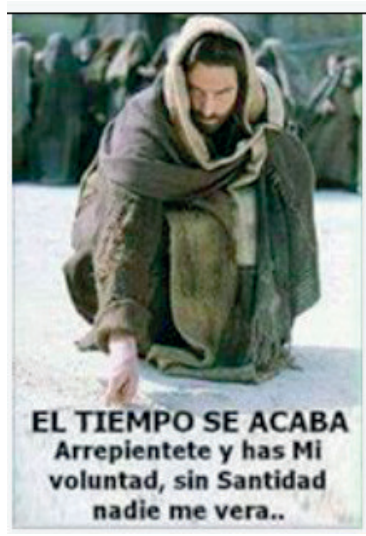

CMHNTM PERÚ.

Por supuesto que el hecho de que los pastores apelen a la Biblia no es una sorpresa. Lo que es inesperado es que también usan la ciencia como fuente de autoridad. Hay menciones continuas al «hecho» de que «Científicamente se considera a un homosexual anormal» y al «hecho» de que no hay un «gen homosexual». Durante mi investigación, encontré un comentario que creo que refleja mejor la relación dibujada entre la verdad religiosa y la verdad científica.

Está científicamente comprobado q sólo hay 2 géneros, xfavor no inventen algo sólo para tener la razón, inclusive muchos psicólogos están de acuerdo con la ciencia y bueno da la casualidad q coincide con la religion.

Los estudios de Foucault sobre el poder pastoral no mencionan apelaciones a la ciencia como autoridad. Sin embargo, sí mencionan que, en las sociedades biopolíticas, el poder soberano a menudo se justifica a través de la ciencia. En este caso, no es que la Biblia sea insuficiente para pastores que necesiten de más pruebas para demostrar lo que están diciendo, sino que la ciencia es más bien usada para convencer a los demás. Este uso de la ciencia como un apoyo adicional para la religión ha sido encontrado por investigadores de otras religiones. Por ejemplo, Puar afirma que en el Islam las referencias constantes a la ciencia se usan para intentar superar la idea contemporánea de que la religión es necesariamente la antítesis de la racionalidad (Puar, 2007, p. 55).

He argumentado que los pastores guían su rebaño a la salvación al compartir la verdad sobre la sexualidad. ¿Pero a quién se dirigen específicamente estos discursos? 
A veces hablan de manera general, aludiendo a terceros LGBTQI* o a defensores de derechos LGBTQI*. Sin embargo, a menudo se dirigen a individuos concretos que participan en la página y que ellos creen haber identificado por sus comentarios o imagen de Facebook como parte de la comunidad LGBTQI*. Además de llamarlos «pecadores», los pastores los urgen a conocer a Dios y a cambiar. Esta figura de pastores que buscan guiar uno a uno a los miembros del rebaño va de la mano con el concepto de poder pastoral de Foucault, donde la labor del pastor se concentra también en el individuo (Carrete, 2013, p. 375; Foucault, 2007, p. 128).

En el desempeño de sus deberes de guía, los pastores no están libres de desafíos. Así como, para Foucault, el soberano tiene enemigos que intentan derrocarlo, los pastores tienen dos enemigos externos que buscan guiar a la gente por el camino equivocado: el diablo y el gobierno. «Entiendan que la homoxualidad es un espiritu diabolico Que se le mete a la persona, Nada mas, El diablo termina por confundirte, pero Dios ama a todos por igual,»; «BASTA DE POLÍTICOS CORRUPTOS Y SIN DIOS».

Para asegurar la salvación de su rebaño, los pastores necesitan despojar al demonio del poder y convencer al gobierno de que cambie los planes de estudio. El grupo de Facebook, por supuesto, es uno de los lugares para hacerlo. Pero hay un segundo sitio: las calles. Es por eso, que CMHNTM PERÚ también es un espacio para organizar movilizaciones contra la «ideología de género».

Finalmente, es interesante que los pastores, además de considerar que tienen un deber en las redes sociales y en las calles, también se consideran los guías de sus propios hijos, una tarea que se menciona - aunque no se ejerce- en CMHNTM PERÚ: «somos los padres encargados de guiar y enseñar a nuestros hijos».

\section{PODER DISCIPLINARIO Y BIOPODER:A TRAVÉS DEL LENTE DEL PASTOR}

El poder disciplinario se refiere al poder que se ejerce «sobre y a través del individuo, el cuerpo y sus capacidades» (Dean, 2010, p. 29). Clasifica cada detalle de la vida como obligatorio o prohibido, poniendo más énfasis en cómo las personas deben actuar que en cómo no deben actuar (Foucault, 2007, p. 46; Stone, 2013, p. 361), y tiene como objetivo la normalización de los cuerpos (Simons, 2013, p. 306; Foucault, 2007, pp. 75-58). El biopoder, por su parte, se ocupa del control y la gestión de las poblaciones en su conjunto (Oksala, 2013, p. 321), enfocándose, entre otras cosas, en las tasas de natalidad y mortalidad (Simons, 2013, p. 306). En el biopoder, el conocimiento experto y científico es clave para el gobierno de las poblaciones (Oksala, 2013, pp. 322, 327). 
Cuando los pastores guían su rebaño a la salvación, no se limitan a compartir la palabra de Dios: también le dan instrucciones detalladas sobre cómo deben actuar y reproducirse. Hacer cortes claros entre el poder pastoral, el poder disciplinario y el biopoder es imposible, ya que se ejercen juntos, pero sí puedo intentar mostrar cómo los pastores reconfiguran el poder disciplinario y el biopoder a través del lente del poder pastoral.

Una forma en que los pastores buscan controlar su rebaño es haciendo que los demás se «arrepientan». «[...] justamente porque los amamos [a los homosexuales] les decimos ARREPIENTANSE Dios los ama». Arrepentirse no es más que volverse heterosexual. Los pastores están allí para ayudar en el proceso de arrepentimiento, explicando que es necesario orar y reconocer los pecados de uno: «También les estamos diciendo que esas personas PUEDEN SANAR, con la ayuda de un buen psiquiatra y acompañados de mucha oración; el poder de Dios puede obrar». Sugerir el arrepentimiento y la oración como formas de alcanzar la salvación también muestra cómo el poder religioso es desinstitucionalizado. No solo es posible que todos puedan ser pastores, sino que también pueden obtener la salvación desde la comodidad de sus propios hogares, sin la necesidad de un pastor «oficial». Así, momentos pastorales claves del cristianismo, como el poder sacramental, el bautismo, la comunión y la penitencia (Foucault, 2007, p. 153), dan paso a prácticas privadas.

\section{Figura 7}

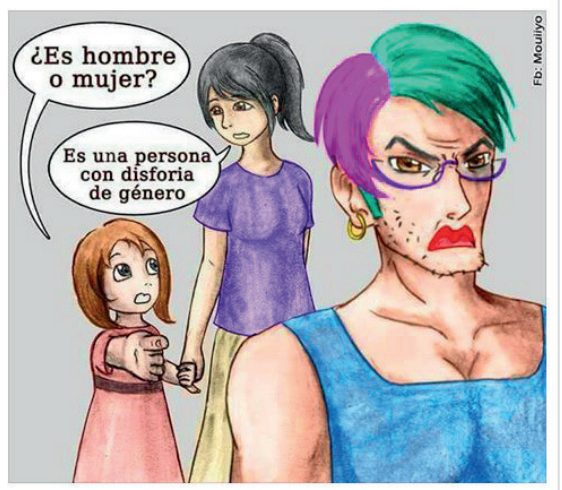

CMHNTM PERÚ.

$\mathrm{Al}$ creer que las personas pueden cambiar si lo desean, los pastores configuran los cuerpos y deseos de las personas LGBTQI* como moldeables. Ellos 
argumentan que «hay muchos testimonios de homosexuales cambiados por el poder de Dios». La sexualidad es algo que puede «normalizarse» (es decir, convertirse en heterosexual) y los cuerpos-almas se convierten en objetos de un poder disciplinario que busca esta «normalización». Esta incluye cambiar la apariencia externa. Como mencioné, las personas LBTQI* a menudo son retratadas, de manera caricaturesca, como trans. Al entender a los individuos LGBTQI* como personas que rompen el vínculo entre la norma (heterosexualidad) y la «forma corporal» (vestimenta «normal») (Mahmood, 2005, p. 23), la identidad de género se convierte en algo que puede ser «detectado» fácilmente.

CMHNTM PERÚ es uno de los espacios elegidos por los pastores para «normalizar» los cuerpos a través de la enseñanza, la guía y la configuración de personas no heterosexuales como anormales. El sitio, sin embargo, también es un lugar donde los pastores difunden la necesidad de que más personas actúen como pastores e impongan disciplina en dos espacios adicionales: la escuela y el hogar. La página es, pues, un lugar para discutir acciones futuras y para mostrar a otros cómo también pueden ser pastores.

Creyendo estar ante el peligro de que la «ideología de género» se imponga en las escuelas y que los niños sean «inducidos a serlo [homosexuales o lesbianas] a muy temprana edad, si ellos no tienen poder de decisión», los pastores-padres tratan de reclamar este espacio al gobierno. Quieren ser los encargados de lo que se les enseñe a sus hijos sobre la sexualidad en las escuelas. $\mathrm{O}$, más precisamente, quieren estar a cargo del silencio: están convencidos de que los temas sexuales son un asunto de los padres y no de los maestros: «la educacion sexual es de los Padres y no del Estado»; «Lo unico q se pide al gobierno es q se respete la familia constituida entre un hombre y mujer e hijos y no confundan y promuevan el homosexualismo». La idea de Foucault de las escuelas como lugares para ejercer la disciplina y lograr el «comportamiento ordenado» (Rabinow, 1991, p. 17) se reconfigura en este contexto: ya no es un espacio donde debe enseñarse un comportamiento «correcto», sino donde al menos no se debe enseñar el tipo de comportamiento que los privará de la salvación.

$\mathrm{Y}$ al igual que la escuela debe ser reclamada para evitar que se convierta en un lugar de enseñanzas peligrosas, los hogares son el último frente a ser protegido. Por supuesto, quieren que todos los homosexuales se arrepientan y se salven, pero si las personas LGBTQI* deciden que no van a seguir el camino de Dios, al menos no deberían «meterse» con sus hijos: «no dejemos que la muerte entre a nuestras cámaras, no dejemos que la oscuridad invada nuestras casas, cada uno encienda su lampara en su hogar». 
El hecho de que los individuos luchen contra la «ideología de género» en las escuelas y que hayan elegido esto como su objetivo principal en una lucha más grande contra la comunidad LGBTQI* apunta a un fenómeno que no es exclusivamente peruano. Hunter sostiene que, luego de la despenalización de las prácticas no heterosexuales, aquellos que se oponen a los derechos LGBTQI* tienen más probabilidades de centrarse en «contener» su propagación (Hunter, 2004, p. 1542). Puar asegura que una de estas tácticas de contención es precisamente valerse de la infancia, por ejemplo, cuestionando si las personas LGBTQI* pueden ser padres adecuados (Puar, 2007, pp. 114-115).

Finalmente, es importante tener en cuenta que los pastores no solo se centran en la normalización de los cuerpos y las almas individuales, sino que también se preocupan por el manejo de la población (es decir, en ejercer biopoder) Me refiero a la idea de que la heterosexualidad es la única vía de supervivencia de nuestra especie, mencionada constantemente en CMHNTM PERÚ: «Dios nos hizo mujeres, para formar parejas con hombres y gracias a Dios que de papá y mamá nacimos nosotros, por que nunca nacerá un niño de dos mujeres ó de dos hombres»; «Solo DIOS a creo hombre y mjer para la expansion de la tierra macho y embra enlos animales». Las identidades LGBTQI* no son únicamente una amenaza para la salvación individual, sino para toda la raza humana, e incluso para las almas futuras. Este punto está profundamente relacionado con el control de cada cuerpo. Foucault ya decía que la sexualidad constituye un vínculo entre el poder disciplinario y el biopoder (Foucault, 1998, p. 147; Rabinow, 1991, p. 67). El control de la población en su conjunto requiere el control de los cuerpos sexuales. La sexualidad, por lo tanto, «asume una posición privilegiada, ya que sus efectos se sitúan en el nivel micro del cuerpo y en el nivel macro de una población» (Lemke, 2011, p. 39). En este caso, los pastores ven la heterosexualidad como una forma de asegurar tanto la salvación de toda la población como la salvación de cada alma-cuerpo.

\section{PODER SOBERANO: CUERPOS-ALMAS NO HETEROSEXUALES Y LA CONDENA ETERNA}

Para Foucault, el soberano tenía el poder de decidir quién podía vivir y quién era dejado morir (Oksala, 2013, p. 321; Allen, 2013, p. 359). Tradicionalmente, ejercía su poder cuando se sentía en riesgo: podía deshacerse de la vida de sus súbditos enviándolos a la guerra, y podía condenar a aquellos que habían cometido un crimen a la pena capital (Allen, 2013, p. 359; Foucault, 1998, p. 135). Con la Ilustración, el ejercicio del poder soberano se transformó (Schrift, 2013, 
p. 90) y se convirtió en un elemento adicional al ejercicio productivo del biopoder (Oksala, 2013, p. 321; Allen, 2013, p. 360; Foucault, 1998, p. 136). Los asesinatos ya no se cometían en nombre de la supervivencia del soberano (Foucault, 1998, pp. 136-137), y solo eran aceptables para garantizar la salud y la supervivencia de la sociedad (Oksala, 2013, p. 323).

En CMHNTM PERÚ, el poder soberano se ejerce bajo una configuración distinta de la salud de la sociedad: la salvación de las almas-cuerpos del rebaño. El mensaje de los pastores es que, si no se dejan guiar, el soberano, Dios, los condenará a muerte eterna. El hecho de que «los homosexuales no heredaran el reyno de Dios» a menudo está respaldado por Corintios 6:9: «¿No sabéis que los injustos no heredarán el reino de Dios?». El que sea Dios quien determina quién es condenado y quién es salvado también significa que el poder de tomar la vida es absoluto. No hay forma de escapar de Dios, porque es omnisciente, el panóptico definitivo.

Hay un sentido adicional en el que las almas-cuerpos LGBTQI* son condenados a muerte: están configurados como cuerpos moribundos. Están asociados con una enfermedad que necesita ser «curada» y que suele no mencionarse, pero es evidente: la no heterosexualidad. A menudo también se piensa que los individuos LGBTQI* están destinados a morir de sida: «a toda esta jente con mente torcida le gustaria que sus hijos se contajien de sida por andar acostandose entre hombres por eso pueblo peruano oremos a Dios». Relacionar a las personas LGBTQI* con enfermedades no es algo nuevo. Hunter encuentra que la conexión de la homosexualidad con la enfermedad proviene desde antes la aparición del sida (Hunter, 2004, p. 1542). Butler también ha explorado la relación entre el homosexual (masculino) y la enfermedad, encontrando que históricamente ha habido discursos que configuran al homosexual (masculino) como «siempre moribundo», y que los cuerpos homosexuales contemporáneos aún se construyen como patológicos (Butler, 1992, p. 357). El sida es «una intensificación y consolidación de la misma tradición» (Butler, 1992, p. 358).

Las menciones a la enfermedad y la condena eterna en la página a menudo se dirigen a toda la población, pero a veces también a participantes individuales.

[Comentarista de sexo masculino A]: Pues ire con mi novio [a la protesta]. [Comentarista B]: Arderás en el infierno.

[Comentarista E]: [ser homosexual] No es genético [...]

[Comentarista F]: Endemoniado!! arrepientete sino te irás al infierno [...]

Vemos así también que, en CMHNTM PERÚ, el ejercicio del poder soberano tiene algo en común con las antiguas expresiones del poder de la muerte, donde 
era importante que este poder no estuviera oculto (Elliot, 2013, p. 359). En este espacio, la muerte es algo que se discute, se habla, se comparte y se teme.

Hasta ahora he discutido expresiones de poder soberano que son una constante en CMHNTM PERÚ. Sin embargo, en el período de mi análisis, y por un tiempo limitado, dos eventos dieron pie a líneas de discurso muy particulares. Primero, el fenómeno El Niño durante el verano de 2017, que causó lluvias extremas, inundaciones y huaicos en todo el Perú. Murieron al menos 130 personas y más de 1 millón fueron materialmente afectadas («Fenómeno El Niño», 2017; «COEN: Estragos por», 2017). Durante las peores semanas de la crisis, muchos comentarios interpretaban los sucesos como un castigo divino al gobierno por fomentar la «ideología de género»: «El castigo del Cielo -con Apus incluidos- está cayendo sobre el gobierno de PPK»; «esto que esta pasando con los desbordes de rios y huaycos: son un juicio de Dios contra el Gobierno del Perú»».

El segundo evento fue un escándalo que involucró al líder del Movimiento Misionero Mundial en el Perú, una importante iglesia evangélica, quien en marzo de 2017 hizo la siguiente declaración: «Los homosexuales deben morir al igual que los corruptos, ateos porque no son obra de Dios. Si encuentran dos mujeres teniendo sexo, maten a las dos» («Fiscalía investiga», 2017). En CHMNTM PERÚ, varios participantes reaccionaron a las noticias defendiéndolo y afirmando que solo estaba siguiendo el mandato de Dios: «la palabra dice que los matemos como animales, hay que purificar la tierra de estas bestias, amén, hermano»; «el pastor citó durante su prédica un pasaje bíblico del libro de Levítico, capítulo 20, que habla sobre las penas para actos de inmoralidad según leyes del antiguo testamento. 'Si encuentran dos mujeres teniendo sexo, maten a las dos [...]'». La muerte se convierte en algo en que las personas pueden tomar con sus propias manos.

Aunque, como dije, el discurso mencionado estuvo básicamente circunscrito a ese momento determinado, en general los pastores entienden que Dios no solo es productivo, sino también destructivo: «te advirtieron que ese Dios era amor, pero también juzga y castiga!»; «Dios es amor pero también fuego consumidor». Además, los pastores creen que se encuentran en una «guerra» contra la «ideología de género», donde Jesús y Dios son los «capitanes».

En su estudio del poder pastoral cristiano, Foucault argumentó que la aparente paradoja de que Dios es creador y destructor puede entenderse porque, si bien el pastor debe cuidar a cada oveja, a veces la salud del rebaño requiere sacrificar a algunos miembros (Foucault, 2007, p. 169). En el caso de CMHNTM PERÚ, algo similar parece estar sucediendo: la violencia y la muerte (eterna o no) a 
veces se considerarían necesarias si un individuo LGBTQI* demuestra que no puede ser cambiado.

El análisis de Foucault del racismo es útil para entender lo que está sucediendo en CHMNTM PERÚ. Al estudiar el racismo en la Alemania nazi, a Foucault le sorprendió que un grupo de personas tan concentradas en la vida hubiera construido una enorme máquina de la muerte. Encontró que los nazis argumentaban que matar a la raza inferior era necesario para la salud del resto de la población. Esta necesidad estuvo (supuestamente) legitimada por un discurso biocientífico (Foucault, 1998, p. 138; Oksala, 2013, p. 323). Sostengo que — con evidentes diferencias - está ocurriendo un fenómeno similar en CMHNTM PERÚ, pero uno que, nuevamente, debe entenderse bajo la óptica del poder pastoral. La condena eterna de individuos LGBTQI* que no se arrepienten se justifica utilizando la salud de todo el rebaño como un argumento. La única manera de que la población se mantenga saludable y obtenga la salvación es seguir la voluntad de Dios y deshacerse de las «malas semillas». Deben ser excluidos de todos los espacios compartidos, protegiendo así a los niños y al futuro de la sociedad. Y la única manera de que el Reino de Dios persista en el tiempo es excluir de él a los pecadores.

Para este momento, la relación clave entre el poder pastoral y el poder soberano ya debería ser evidente. El poder pastoral justifica el ejercicio del poder soberano. $\mathrm{Y}$ el poder soberano constituye la amenaza que da fuerza al poder pastoral. Buscar la salvación nunca es más atractivo que cuando la alternativa es la condena eterna.

\section{NECROPODER: LGBTQI* COMO UNA POBLACIÓN MUERTA EN VIDA}

Las ideas de biopoder y poder soberano también han dado paso a una figura muy destacada en la academia contemporánea: el necropoder. Para Achille Mbembe, la obra de Foucault no era capaz de «dar cuenta de las formas contemporáneas de subyugación de la vida al poder de la muerte» (Mbembe, 2003, pp. 39-40). $\mathrm{Su}$ concepto de necropoder, una «formación de terror específica», busca llenar el vacío. Mbembe habla de poblaciones contemporáneas muertas en vida, que existen en mundos de la muerte (Mbembe, 2003, p. 40). Para él, marcar a las personas para que mueran es una herramienta política útil que utiliza el soberano (De Mauro, 2015, p. 17), que puede apelar a la excepción, la emergencia y a un enemigo ficcional (Mbembe, 2003, p. 16) para proteger la vida de quienes se consideran dignos de vivir (Wright, 2011, p. 709). Necropoder, entonces, también 
se refiere al matar y dejar morir que está autorizado «en nombre de fomentar y proteger la vida de otros», por lo que la muerte ocurre en nombre de la vida (Lamble, 2013, p. 162).

Considero que Mbembe no toma en cuenta que los conceptos de poder soberano, biopoder y racismo de Foucault podrían por sí mismos explicar la forma de subyugación de la vida al poder de la muerte. Sin embargo, pienso que el necropoder es una categoría útil para conceptualizar mis hallazgos en CMHNTM PERÚ. Este nos exhorta a observar las formaciones de terror, las poblaciones de muertos vivos y la «co-presencia simbiótica de la vida y la muerte» (Haritaworn et al., 2014, p. 2). Quizás la principal manera en la que Mbembe trata de diferenciarse de Foucault es demostrando que el poder de la muerte no es uno que simplemente se mantiene en las sociedades contemporáneas: el necropoder y el biopoder siempre, y necesariamente, están unidos (Puar, 2007, pp. 32-33). En cierto sentido, el necropoder de Mbembe no es más que la configuración contemporánea del poder soberano, un concepto que nos insta a ver cómo el antiguo poder soberano está impregnando todo, siempre presente y reconfigurando la gestión de las poblaciones.

Sea como fuere, el concepto de necropoder se ha utilizado para comprender varios fenómenos contemporáneos. Puar (2007) ha liderado el camino en la investigación sobre necropolítica queer, enfocada en «las muchas formas de muerte que acompañan y condicionan los reclamos queer a la vida, la visibilidad y la protección» (Haritaworn et al., 2014, p. 10). Estos estudios han sido claves para mostrar cómo el necropoder es a menudo parte de la existencia diaria de individuos LGBTQI* y exploran temas como las cárceles como sitios de necropoder (Gossett, 2014; Lamble, 2014) y los cuerpos de color trans femeninos como «víctimas» de necropoder (Edelman, 2014).

Siguiendo a Mbembe, se podría decir que, para los pastores, las almas-cuerpos LGBTQI* están enfermos, situados fuera de la vida, y constituyen el mundo de la muerte. En este caso, Dios (a través de los pastores) usa este mundo de la muerte para provocar el terror y dar poder a su mensaje. Si la gente quiere la salvación y evitar la terrible lucha que enfrentan las almas LGBTQI* moribundas, deben seguir la voluntad de Dios. En este sentido, Dios (a través de los pastores) ejerce el necropoder y subyuga la vida de los individuos al poder de la muerte. La vida debe ser vivida de acuerdo con las enseñanzas de Dios, porque si no la muerte es eterna. De esta manera, el necropoder y el poder pastoral actúan juntos. El terror de la condena determina y legitima el objetivo del poder pastoral (y disciplinario y biopoder) de controlar cada detalle de la existencia de individuos y guiarlos hacia 
la salvación. Tratar de evitar el terror, después de todo, solo tiene sentido si esto es posible. Además, ¿qué significa guiar a alguien a la salvación sin la amenaza de la muerte? ¿Cuál es la formación de terror definitiva, si no la muerte eterna?

\section{CONCLUSIÓN}

En este trabajo analizo CMHNTM PERÚ. Sostengo que los participantes religiosos en la página que se oponen a la «ideología de género» están actuando como pastores. El ejercicio del biopoder y del poder disciplinario, también presente en la página, debe entenderse como reconfigurado a través del poder pastoral. Lo mismo ocurre con el poder soberano, que se legitima a través del poder pastoral: la muerte eterna de personas no heterosexuales que no se arrepienten y no encuentran que Dios está justificada por la salud del rebaño y el éxito de su guía para la salvación. Finalmente, muestro cómo la configuración específica del poder soberano que estoy estudiando es también una instancia del necropoder.

A este respecto, debo agregar que durante mi investigación me quedó claro que, aunque CMHNTM PERÚ se creó originalmente como una página para luchar contra la «ideología de género» en la escuela, en la práctica es mucho más que eso. En realidad, se ha convertido en un lugar donde los pastores intentan normalizar a las personas LGBTQI* y reclamar otros espacios, como el hogar. También es un lugar de formaciones de terror y de condena a las almas-cuerpos a la muerte (eterna).

\section{REFERENCIAS BIBLIOGRÁFICAS}

Agamben, G. (1998). Introduction. En G. Agamben, Homo Sacer. Sovereign Power and Bare Life (pp. 1-8). Standford: Standford University Press.

Allen, A. (2013). Power and the Subject. En C. Falzon, T. O'Leary y J. Sawicki (eds.), A companion to Foucault (pp. 337-352). Chichester; West Sussex; UK: WileyBlackwell.

Basset, E. y K. O'Riordan (2002). Ethics of internet research: Contesting the human subjects research model. Ethics and Information Technology, 4, 233-247.

Bayard de Volo, L. (2009). Participant Observation, Politics and Power Relations: Nicaraguan Mothers and U.S. Casino Waitresses. En E. Schatz (ed.), Political Ethnography: what Immersion Contributes to the Study of Power (pp. 217-236). Chicago: University of Chicago Press. 
Bernauer, J. y S. J. Forward (1999). Cry of Spirit. En J. Carrette (ed.), Religion and culture. Michel Foucault (pp. xi-xviii). Nueva York: Routledge.

Berríos, M. (2007, 30 agosto). Minedu apelará fallo que anula enfoque de género. La República. Recuperado de: http://www.larepublica.pe/sociedad/1081296-mineduapelara-fallo-que-anula-enfoque-de-genero-en-curriculo

Butler, J. (1992). Sexual Inversions. En D. Stanton (ed.), Discourses of Sexuality. From Aristotle to Aids (pp. 344-361). Ann Arbor, MI: The University of Michigan Press.

Carabine, J. (2003). Unmarried Motherhood 1830-1990: A Genealogical Analysis. En M. Wetherell, S. Taylor y S. Yates (eds.), Discourse as Data: A Guide for Analysis (pp. 267-310). Londres: Sage.

Carrette, J. (1999). Prologue to a confession of the flesh. En D. Stanton (ed.), Religion and culture. Michel Foucault (pp.1-47). Nueva York: Routledge. pp. 1-47.

Carrette, J. (2013). Foucault, Religion, and Pastoral Power. En C. Falzon, T. O'Leary y J. Sawicki (eds.), A companion to Foucault (pp. 368-383). Chichester, West Sussex, UK: Wiley-Blackwell. https://doi.org/10.1002/9781118324905.ch18

Castro, J. (2017, 4 de marzo). El poderoso reino de los evangélicos y sus prósperos operadores en la tierra. Ojo público. Recuperado de: http://ojo-publico.com/384/ elpoderoso-reino-de-los-evangelicos-y-sus-operadores-en-la-tierra.

Clarke A., J. Shim, L. Mamo, J. Fosket y J. Fishman (2003). Biomedicalization: Technoscientific transformations of health, illness, and U.S. biomedicine. American Sociological Review, 68(2), 161-194. https://doi.org/10.2307/1519765

COEN: Estragos por el Fenómeno del Niño dejan más de 1 millón de afectados. (2017, 27 abril). América TV. Recuperado de: Con Mis Hijos No Te Metas PERÚ-Oficial. (2016). En Facebook [Página de grupo] (última fecha de acceso: 26.08.17). https://www.facebook.com/pg/conmishijosnotemetasperuoficial/community/

Currículo Escolar: Estos son los cambios que hizo el Minedu (2017, 9 de marzo). La República. Recuperado de: http://larepublica.pe/sociedad/854963-curriculoescolarestos-son-los-cambios-que-hizo-el-minedu.

De Mauro, M. (2015). Trans* necropolitics. Gender Identity Law in Argentina. Sexualidad, Salud y Sociedad. Revista Latinoamericana, 20, 10-27.

Dean, M. (2010). Governmentality. Power and Rule in Modern Society. Londres: Sage.

Desmond Arias, E. (2009). Ethnography and the Study of Latin American Politics: An Agenda for Research. En E. Schatz (ed.), Political Ethnography: what Immersion Contributes to the Study of Power (pp. 239-254). Chicago, IL: University of Chicago Press. 
Edelman, E.A. (2014). «Walking while transgender». Necropolitical regulations of trans feminine bodies of colour in the nation's capital. En J. Haritaworn, A. Kunstman and S. Posocco. Queer Necropolitics (pp. 172-190). USA; Canada: Routledge.

Evangelical Manifesto Steering Committee (2008). An Evangelical Manifesto. A Declaration of Evangelical Identity and Public Commitment. Washington D.C. http:// evangelicalmanifesto.com/wpcontent/uploads/2016/03/Evangelical_Manifesto. pdf

Fassin, D. (2009). Another Politics of Life is Possible. Theory Culture Society, 26(5), 44-60. https://doi.org/10.1177/0263276409106349

Federman, C. y D. Holmes (2005). Breaking bodies into pieces: time, torture and biopower. Critical Criminology, 13, 327-345. https://doi.org/10.1007/s10612005-3187-9

Fenómeno El Niño Costero dejó 63 muertos en el norte (2017, 1 mayo). Perú.21. http:// peru21.pe/lima/fenomeno-nino-costero-dejo-63-muertos-norte-74731.

Fiscalía investiga a pastor tras mensaje homofóbico y de odio (2017, 6 marzo). El Comercio. http:/elcomercio.pe/lima/fiscalia-investiga-pastormensaje-homofobico-odio-142987.

Foucault, M. (2007). Security, Territory, Population: Lectures at the Collège de France 1977-1978. Nueva York: Palgrave Macmillan.

Foucault, M. (1982). Subject and Power. Critical Inquiry, 8(4), 777-795.

Foucault, M. (1991). Truth and power. En Paul Rabinow (ed.), The Foucault reader (pp. 51-75). Harmondsworth: Penguin.

Foucault, M. (1998). The will to knowledge. The history of sexuality Volume 1. London: Penguin Books.

Foucault, M. (2002). Archaeology of knowledge. Londres, Nueva York: Routledge.

Fujimorismo respaldó polémica movilización en contra del nuevo currículo escolar (2017, 4 marzo). La República. Recuperado de: http://larepublica.pe/ politica/853663-fujimorismo-respalda-polemica-movilizacion-en-contra-delnuevo-curriculoescolar.

Gossett, C. (2014). We will not rest in peace: AIDS activism, black radicalism, queer and/or trans resistance. En J. Haritaworn, A. Kunstman y S. Posocco. Queer Necropolitics (pp. 31-50). USA, Canada: Routledge.

Hall, S. (2004). Foucault: Power, Knowledge and Discourse. En M. Wetherell, S. Taylor, S. y S. Yates (eds.), Discourse Theory and Practice (pp. 71-81). Londres: Sage.

Halperin, Sandra y Oliver Heath (2012). Political Research: Methods and Practical Skills. Oxford: Oxford University Press. 
Hansen, L. (2006). Security as practice. Discourse analysis and the Bosnian war. Abingdon: Routledge.

Haritaworn, J., A. Kunstman y S. Posocco (2014). Queer Necropolitics. USA, Canada: Routledge.

http://www.americatv.com.pe/noticias/actualidad/coen-estragos-fenomeno-ninodejanmas-1-millon-afectados-n274311.

Hunter, N.D (2004). Sexual Orientation and the Paradox of the Heightened Scrutiny. Michigan Law Review, 102(7), 1528-1554. https://doi.org/10.2307/4141913

Kozinets, R. (2015). Netnography: Redefined. Londres: Sage.

Lamble, S. (2014). Queer investments in punitiveness: sexual citizenship, social movements and the expanding carceral state. En J. Haritaworn, A. Kunstman y S. Posocco, Queer Necropolitics (pp. 151-171). USA, Canada: Routledge.

Lemke, T., M. Casper y L. Moore (2011). Biopolitics: An Advanced Introduction. New York: NYU Press.

Mahmood, S. (2005). Politics of Piety. The Islamic Revival and the Feminist Subject. Princeton, Oxford: Princeton University Press. https://doi.org/10.2307/j. ctvet00cf

Mbembe, A. (2003). Necropolitics. Public Culture, 15(1), 11-40.

McCuaig, L.A. (2012). Dangerous Carers: Pastoral power and the caring teacher of contemporary Australian schooling, Educational Philosophy and Theory. Educational Philosophy and Theory, 44(8), 862-877. https://doi.org/10.1111/ j.1469-5812.2011.00760.x

Meneses, D. (2017). Research Proposal: How are identity and difference constituted and contested within religious discourses about «gender ideology» in Peru? UCL.

Ministerio de Educación (2016). Currículo Nacional de Educación Básica. http://www. minedu.gob.pe/curriculo/pdf/curriculo-nacional-2016-2.pdf

Moreno, J. (2016, 16 agosto). Así fue la marcha contra supuestos cambios en manuales de convivencia. El Tiempo de Colombia. Recuperado de: http://www.eltiempo. com/colombia/otras-ciudades/protestas-contra-cartillas-deideologia-de-generoen-colegios-42293.

O’Collins, Gerald (2017). Catholicism. A very Short Introduction. Oxford: Oxford University Press. https://doi.org/10.1093/actrade/9780199545919.001.0001

Oksala, J. (2013). From Biopower to Governmentality. En C. Falzon, T. O'Leary y J. Sawicki (eds.), A companion to Foucault (pp. 320-336). Chichester, West Sussex, UK: Wiley-Blackwell. 
Pachirat, T. (2009). The Political in Political Ethnography: Dispatches from the Kill Floor. En E. Schatz (ed.), Political Ethnography: What immersion contributes to the study of power (pp. 143-161). Chicago, Londres: University of Chicago Press.

Phew Research Center (2014). Religion in Latin America. Widespread Change in a Historically Catholic Region Full report. Recuperado de: https://www.compassion. com/multimedia/religion-in-latin-america-pewresearch.Pdf

Posocco, S. On the Queer Necropolitics of Transnational Adoption in Guatemala. En Haritaworn, J., Kunstman, A. and S. Posocco. Queer Necropolitics. USA, Canada: Routledge. pp. 72-90.

Puar, J. K. (2007). Terrorist Assemblages. Homonationalism in queer times. Durham, Londres: Duke University Press.

Rabinow, P. (1991). Introduction. En Paul Rabinow (ed.), The Foucault reader. Penguin Books.

Rose, N. (2007). Introduction. En N. Rose, The politics of Life itself. Biomedicine, Power and subjectivity in the twenty first century (pp. 1-8). Princeton, Oxford: Princeton University Press.

Sánchez, W. (2016, 23 de junio). Video: Bolivianos marchan por la vida y la familia ante la ley de identidad de género. Aci prensa. Recuperado de: https://www. aciprensa.com/noticias/video-bolivianos-marchan-por-la-vida-y-lafamilia-anteley-de-identidad-de-genero-99548/

Schatz, E. (2009). Ethnographic Immersion and the Study of Politics. En E. Schatz (ed.), Political Ethnography: What immersion contributes to the study of power (pp. 1-22). Chicago, Londres: University of Chicago Press.

Schrift, A. D. (2013). Discipline and Punish. En C. Falzon, T. O’Leary y J. Sawicki (eds.), A companion to Foucault (pp. 137-153). Chichester, West Sussex: WileyBlackwell.

Schwartz-Shea, P. y D. Yanow (2012). Interpretive Research Design: Concepts and Processes. Londres, Nueva York: Routledge.

Shdaimha, C., R. Stahl y S. F. Schram (2009). En E. Schatz (ed.), Political Ethnography: what Immersion Contributes to the Study of Power (pp. 255-274). Chicago: University of Chicago Press.

Shepherd, L. (2006). Veiled references: Constructions of gender in the Bush administration discourse on the attacks on Afghanistan post-9/11. International Feminist Journal of Politics, 8(1), 19-41. https://doi.org/10.1080/14616740500415425

Shepherd, L. (2008). Gender, violence and Security. Discourse as practice. Londres, Nueva York: Zed Books. 
Shepherd, L. (2010). Women, armed conflict and language - Gender, violence and discourse. International Review of the Red Cross, 92(877), 143-159. https://doi. org/10.1017/s1816383110000093

Simons, J. (2013). Power, Resistance, and Freedom. En C. Falzon, T. O’Leary y J. Sawicki (eds.), A companion to Foucault (pp. 301-309). Chichester, West Sussex, UK: Wiley-Blackwell. https://doi.org/10.1002/9781118324905.ch14

Stone, B.E. (2013). Power, Politics, Racism. En C. Falzon, T. O’Leary y J. Sawicki (eds.), A companion to Foucault (pp. 353-367). Chichester, West Sussex, UK: Wiley-Blackwell. https://doi.org/10.1002/9781118324905.ch17

Taylor, S. (2003). Locating and conducting discourse analytic research. En M. Wetherell, S. Taylor y S. Yates (eds.), Discourse as Data: A Guide for Analysis (pp. 5-48). Sage: Londres.

Volante en A6. (N.d.) Recuperado de http://conmishijosnotemetas.pe

Wilcox, L. (2014). Bodies, Subjects, and Violence in International Relations. En Bodies of Violence: Theorizing Embodied Subjects in International Relations. University Press Scholarship Online. https://doi.org/10.1093/acprof: oso/9780199384488.003.0002

Wiles, R. (2012). What are Qualitative Research Ethics? Londres: Sage. https://doi. org/10.5040/9781849666558 